\title{
Phytobezoar of the Stomach - Laparoscopic Approach
}

\author{
F. Latic E. Zerem \\ University Clinical Center Tuzla, Tuzla, Bosnia and Herzegovina
}

Dear Sir,

We would like to commend Park and Chae [1] for their interesting clinical image entitled 'Phytobezoar of the Stomach', where they described and well illustrated a rare finding of the accumulation of ingested fibrous material in the stomach, which resulted in the formation of a gastric phytobezoar.

They note that modern management usually begins with attempts at chemical dissolution of the bezoar followed by an endoscopic approach as a second treatment modality when chemical dissolution

Fig. 1. Gastroduodenoscopic finding. Endoscopy shows a large phytobezoar in the stomach.

Fig. 2. A large ulcer in the stomach at the place of the phytobezoar which was removed laparoscopically.

Fig. 3. Three small cutaneous scars after laparoscopic removal of the gastric phytobezoar.

Fig. 4. The remains of the phytobezoar after laparoscopic excision. failed. According to the authors, surgery should be performed in cases where other measures have failed.

We had a similar case and we wish to add some comments regarding this topic. We report the case of a 59-year-old woman who was admitted with epigastric pain, nausea, vomiting and feelings of 'a moving ball' in the stomach. Endoscopy revealed a giant phytobezoar in the stomach measuring $12 \mathrm{~cm}$ in its largest diameter (fig. 1) with a large ulcer affecting the gastric mu- cosa (fig. 2). Conservative and endoscopic approaches failed, but we performed a laparoscopic approach instead of open surgery and successfully treated this gastric phytobezoar (fig. 3, 4). We would like to stress that a laparoscopic approach is less invasive compared to open surgery in the treatment of this benign disease.

\section{Reference}

1 ParkJW, Chae HD: Phytobezoar of the stomach. Dig Surg 2010;26:451-452.

2
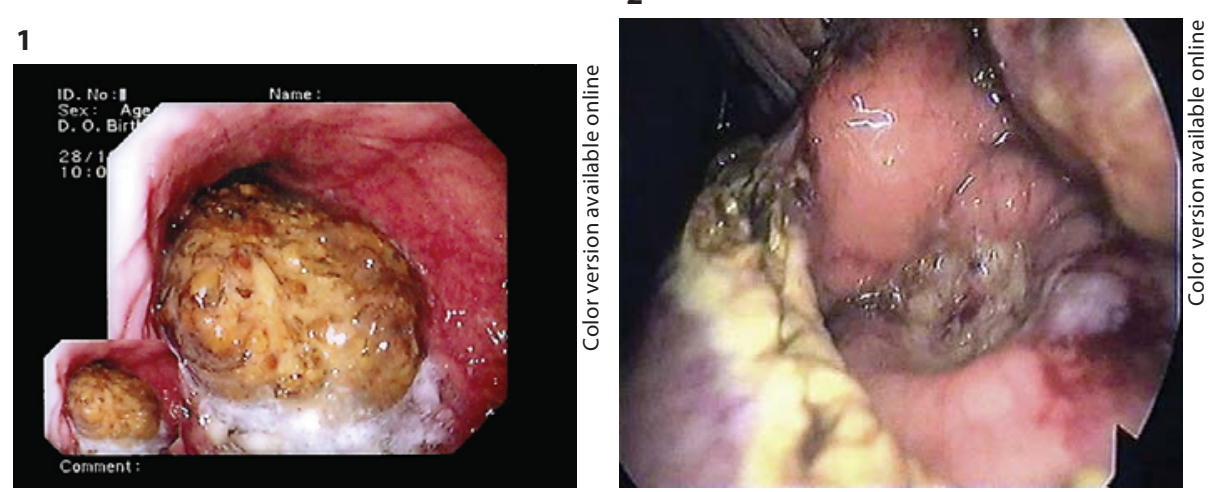

3

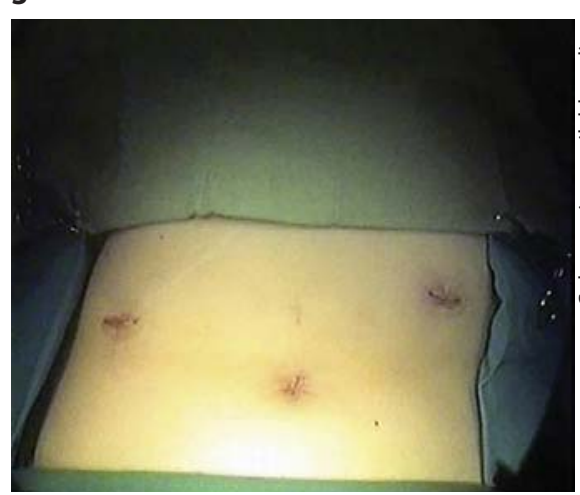

4

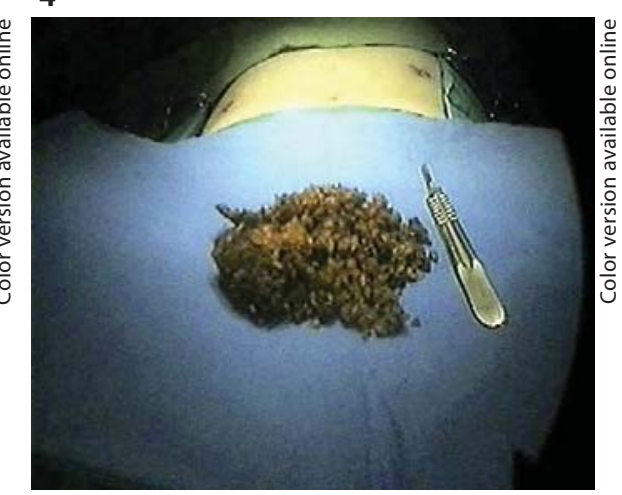

\section{KARGER}

Fax +4161306 1234 E-Mail karger@karger.ch www.karger.com
(C) 2010 S. Karger AG, Basel 0253-4886/10/0274-0338\$26.00/0 www.karger.com/dsu
Enver Zerem

University Clinical Center Tuzla

Izeta Sarajlića F-B/6

BA-75000 Tuzla (Bosnia and Herzegovina)

Tel. +387 6234 4293, Fax +387 250 474, E-Mail zerem@ live.com 